\title{
The use of rotating electric arc for spherical particle production ${ }^{(\cdot)}$
}

\author{
Ioan Bica*
}

\begin{abstract}
This work presents an experimental device designed to obtain spherical particles by means of a rotating electric arc. A rotation frequency of the electric arc of $750 \mathrm{~s}^{-1}$, a voltage of 50 $\mathrm{V}(\mathrm{dc})$ and a current of $100 \mathrm{~A}$ was used. The mass flow rate was $3 \mathrm{~g} \cdot \mathrm{min}^{-1}$. Under these conditions particles of 15 to $20 \mu \mathrm{m}$ in diameter were obtained
\end{abstract}

Keywords Rotating electric arc. Plasma. Powder. Fine particles. Current source. Powder doser.

\section{La utilización del arco eléctrico rotatorio para la producción de partículas esféricas}

Resumen Este trabajo presenta la instalación experimental destinada a la obtención de partículas esféricas utilizando un arco eléctrico rotatorio. Para ello se utilizó una frecuencia de rotación del arco eléctrico de 750 a un voltaje del arco de $50 \mathrm{~V}$ (cc) y una corriente de $100 \mathrm{~A}$. La velocidad de flujo de materia fue de $3 \mathrm{~g}^{\mathrm{min}}$ * obteniéndose particulas de diámetros comprendidos entre 15 y 20 גаm. por anio

micras

Palabras clave: Arco eléctrico rotatorio. Plasma. Polvos. Particulas finas. Fuente de energía. Dosificador de polvos.

\section{INTRODUCTION}

Metallic fine particles obtained by extraction or by flotation and those produced by milling recycled materials (e.g. chamotte, glass, etc.) exhibit irregular shape. In contrast, electric arc or plasmabased technology ${ }^{[1 \text { and 2] }}$ for metal surface covering, magnetofluidic composite materials ${ }^{[3]}$ and electrorheological fluids ${ }^{[4]}$ production, etc. require spherical particles ${ }^{[5-7]}$.

On the other hand, for environment protection reasons, recyclable materials are of interest. For this purpose, we propose an experimental installation for sphere reshaping of powders resulting from the milling of chamotte. In addition, the resulting spherical particles may exhibit controlled coloration which is of interest in decoration and in the painting industry.

\section{EXPERIMENTAL PROCEDURE}

The scheme of the experimental device designed to produce spherical particles using a rotating electric arc is given in figure 1. A general view of the device is presented in figure 2. The device consists of the current source: 1 , the command panel; 2 , the

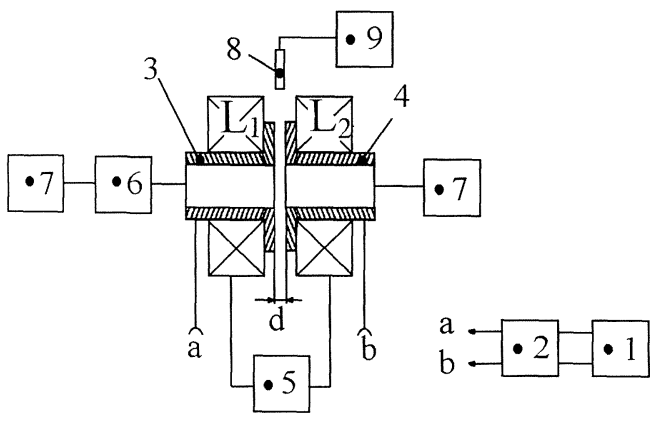

Figure 1. The block scheme of the functional model designed to produce mesoscopic particles through the electric arc method; 1: current source, 2: command panel, 3 and 4: copper electrodes, 5 : current source for supplying the coils L1 and L2, 6: powder doser, 7: argon cylinders equipped with pressure reducers and flowmeters, 8: optical sensor, 9: rotation indicator block, $a, b$ : connection terminals, d: distance between electrodes.

Figura 1. Esquema del bloque del modelo funcional destinado a la producción de partículas esféricas finas mediante arco eléctrico rotatorio; 1: fuente de energía, 2: pupitre de mando, 3 y 4: electrodos de cobre, 5: fuente de energía para la alimentación de las bobinas $L 1$ y L2, 6: dosificador de polvo, 7: bombonas para el gas comprimado (argón) con reductores de presión y rotámetros, 8: medidor óptico, 9: bloque indicador de rotaciones; a y b: bornes de conexión, d: distancia entre electrodos.

(•) Trabajo recibido el día 21 de enero de 2000 y aprobado en su forma final el 8 de mayo de 2000.

(*) Department of Physics. West University of Timisoara. Bd. Vasile Parvan, 1900, Timisoara (Rumania). 


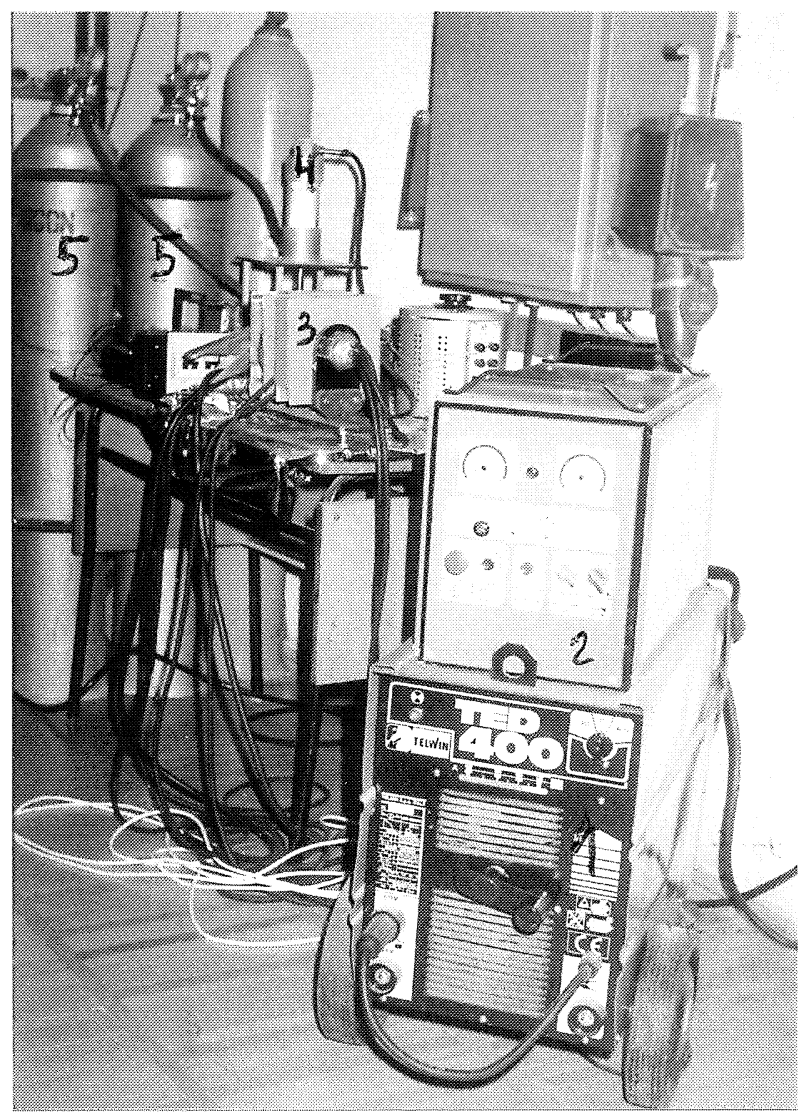

Figure 2. A general view of the devices designed to shape particles as spheres in the rotating electric arc, 1: current source, 2: command panel, 3: coils with electrodes, 4: powder doser; 5 : compressed gas cylinders equipped with pressure reducers and flow meters.

Figura 2. Una vista de conjunto de la instalación destinada a dar forma esférica a las partículas mediante el arco eléctrico rotatorio. 1: fuente de energía, 2: pupitre de mando, 3: bobinas de electrodos, 4: dosificador de polvo, 5: bombonas con gas comprimido y reductores de presión y rotámetros.

electrodes; 3 and 4, the source; 5 the supply of dc power to the coils $L_{1}$ and $L_{2}$, the powder doser 6 , the compressed gas cylinders, the optical sensor 8 and the rotation indicator block 9 . The dc current source is needed to power the electrical discharge between the electrodes. This equipment was obtained by modifying a WIG source, of type TED 400R. The technical characteristics of the current source are the following:

- supply voltage: $3 \times 380 \mathrm{~V}, \mathrm{dc}, \pm 10 \%$;

- idle voltage: $U_{\text {máx }}=110 \mathrm{~V}, \mathrm{dc}, \pm 10 \%$;

- intensity of the continuously adjustable current in the range of $(25 \mathrm{~A}, \mathrm{dc}, \div 200 \mathrm{~A}, \mathrm{dc}) \pm 10 \%$;

The command panel consists of command and inter-blocking blocks for the current source, measure and control devices, high voltage and high

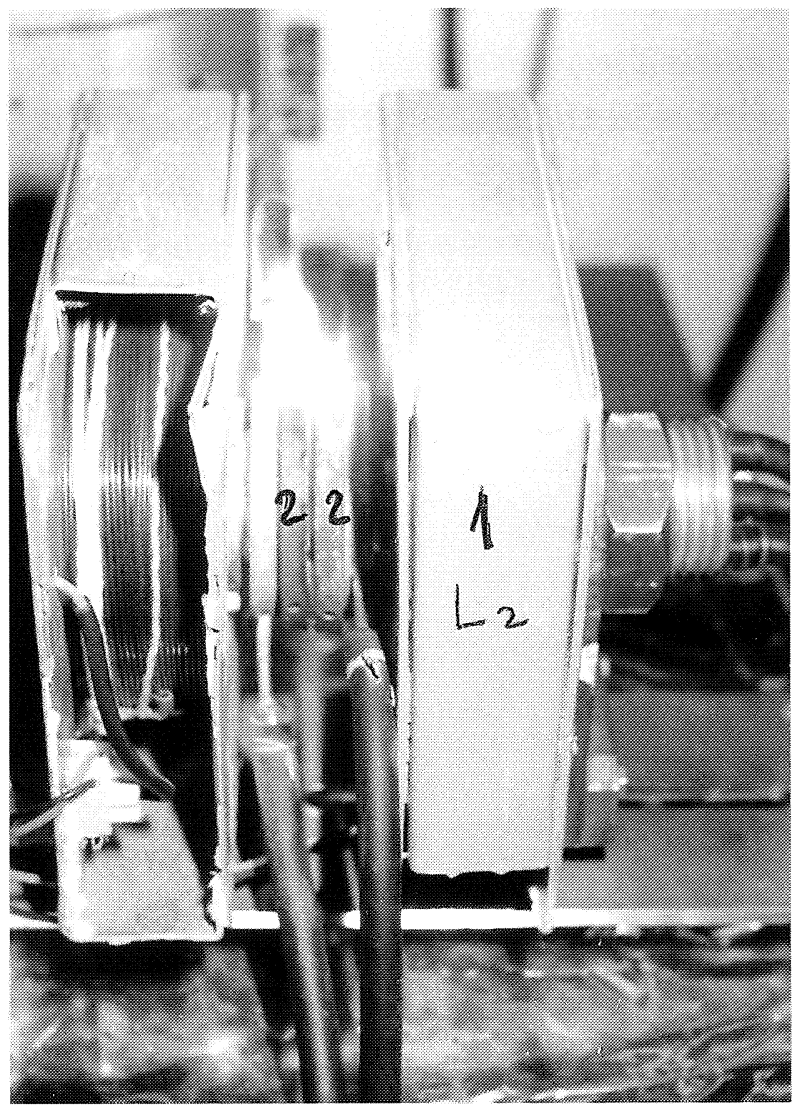

Figure3. General view of the electrodes between which the electric arc was primed; 1: coils, 2: well cooled electrodes.

Figura 3. Vista de conjunto de los electrodos entre los cuales se cebó un arco eléctrico, 1: bobinas, 2: electrodos bien enfriados.

frequency oscillator for automatically priming the electric arc, and a board with terminals for the connecting electrodes (Fig. 1). These electrodes are made of copper, and have a diameter of $80 \mathrm{~mm}$. They are placed in parallel positions. The electric arc is primed between the electrodes (Fig. 3).

When a magnetic field is applied perpendicularly to the electric discharge, the electric arc begins a circular movement on the surface of the electrodes (Fig. 4).

The coils $L_{1}$ and $L_{2}$ in figure 3 and figure 4, respectively, produce a resultant magnetic field perpendicular to electrical discharge axis. The maximum value of the resultant magnetic field induction is $B=30 \mathrm{mT}$, for an electric current intensity supplied by source 5 (Fig. 1) of $28 \mathrm{~A}$, dc.

The powder doser (Fig. 5) is designed to mix the powder with the gas and to transport it into the electrical discharge. The mass flow rate of the powder can be adjusted between $0.2 \mathrm{~g} / \mathrm{min}$ and 25 $\mathrm{g} / \mathrm{min}$, with a $\pm 15 \%$ tolerance. The rotation indicator block measures the frequency of the rotation of the electric arc. The measured 


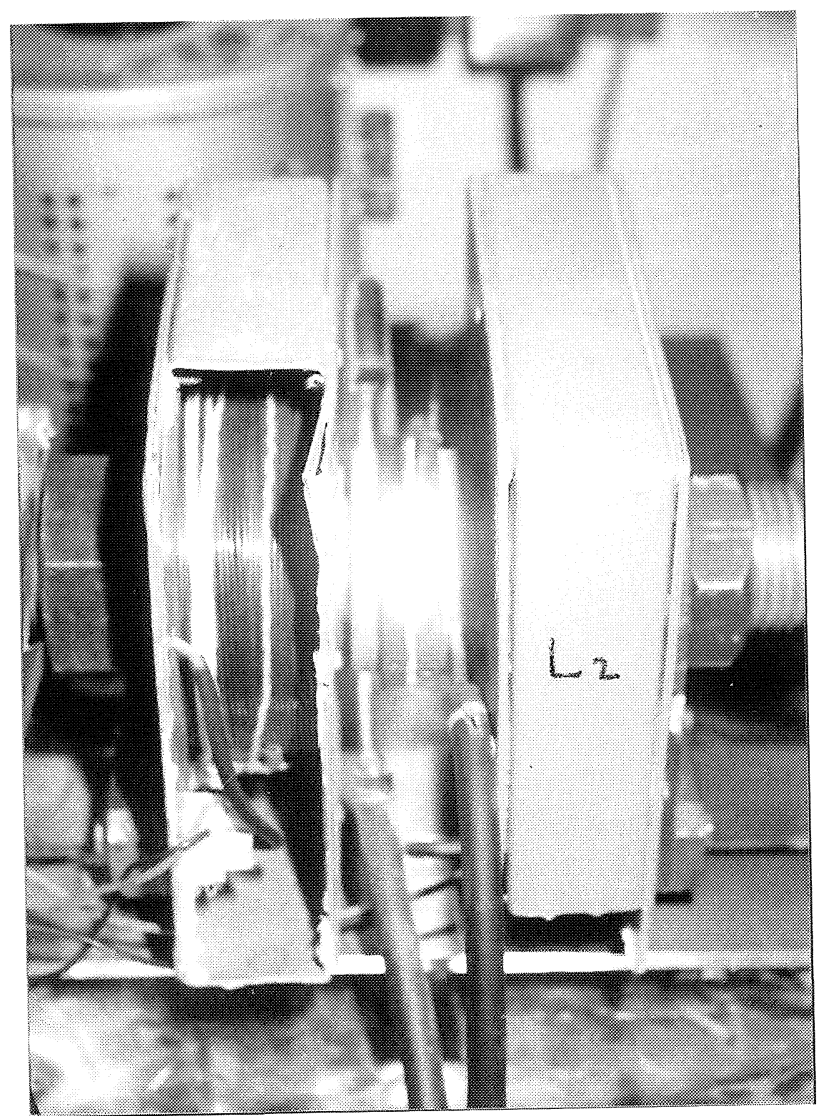

Figure 4. When a magnetic field is applied, perpendicularly to the electric discharge, the electric arc begins a circular movement in the space between the electrodes; magnetic field induction value: $B=24 \mathrm{mT}$; electric current intensity value: $\mathrm{I}=100 \mathrm{~A}$, dc; gas flow rate $(\mathrm{Ar})$ : 10 $\mathrm{Nl} \cdot \mathrm{min}^{-1}$.

Figura 4. Por la aplicación de un campo magnético de inducción magnética $B$, perpendicular a la descarga, el arco eléctrico se mueve circularmente en el espacio que hay entre los electrodos; campo magnético: $B=24 \mathrm{mT}$; intensidad de la corriente de descarga: I = $100 \mathrm{~A}$; Caudal de gas (Ar): $10 \mathrm{Nl} \cdot \mathrm{min}^{-1}$.

frequency is between $5 \mathrm{~s}^{-1} \pm 10 \%$ and $100 \mathrm{~s}^{-1} \pm$ $5 \%$ on the first domain, and between $100 \mathrm{~s}^{-1} \pm$ $5 \%$ and $1,000 \mathrm{~s}^{-1} \pm 5 \%$ on the second domain.

\section{RESULTS AND DISCUSSION}

The coils $L_{1}$ and $L_{2}$ are connected to the dc power supply 4 in figure 5 in such a manner that the resulting magnetic field of induction, $\vec{B}$, is perpendicular to the symmetry axis $x-x_{1}$ (Fig. 6).

The magnetic induction $B$, at the edge of the electrodes is plotted versus the electric current intensity $I_{b}$ through the coils in figure 7 . In order to bring the electric arc into rotation, a force

$$
I B d=6 \pi \eta r v+2 \pi \gamma \varepsilon
$$

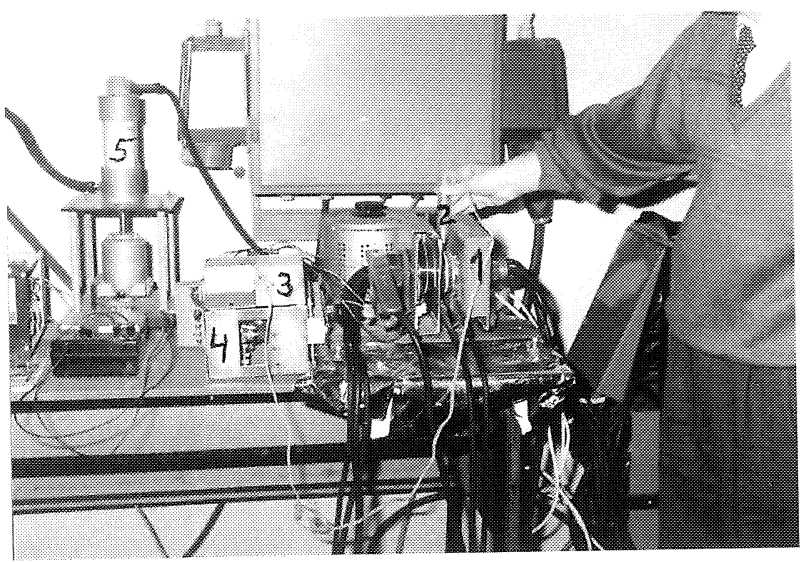

Figure 5. The component parts of the device designed to shape particles as spheres in the plasma of a rotating arc, 1: coils and electrodes ensemble, 2: optical sensor, 3: rotation indicator block, 4: dc source supplying the coils, 5: powder doser.

Figura 5. Elementos componentes de la instalación para dar forma a los polvos mediante el plasma del arco eléctrico rotatorio, 1: conjunto de bobinas con electrodos, 2: medidor óptico, 3: bloque para indicar las rotaciones, 4: fuente de corriente continua para la alimentación de la bobina, 5: dosificador de polvos.

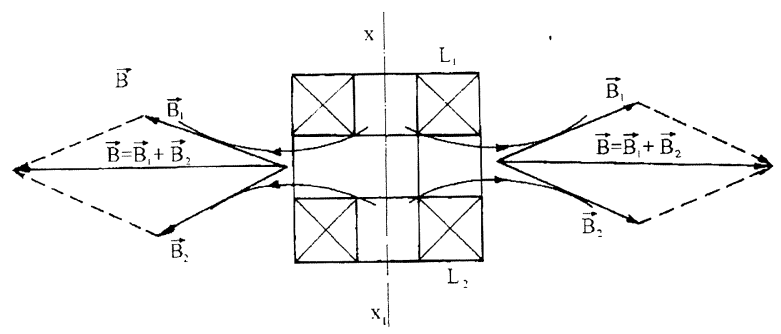

Figure 6. The configuration of the magnetic field generated by the coils $L_{1}$ and $L_{2}$.

Figura 6. La configuración del campo magnético generado por las bobinas $L_{1}$ y $L_{2}$.

is needed, where $d$ is the distance between the electrodes, $\eta$ is the dynamic viscosity of the medium in which the electric arc moves, $v$ is the tangent velocity, $\gamma$ is the superficial strain of the melt-gas system, $r$ is the radius of the anodic spot, and, finally, $\varepsilon$ is the curvature radius of the separation surface of the melt-gas system.

While working, superficial melting of the copper electrodes occurs (Fig. 8). By denoting with $\gamma$ the superficial stress in the melt-argon system, one obtains from equation (1), after simple calculation, the frequency $v$ of the circular motion of the electric arc:

$$
v=\frac{8.45 \cdot 10^{-3}}{\eta \mathrm{rR}}(\mathrm{IBd}-2 \pi \gamma \varepsilon)
$$




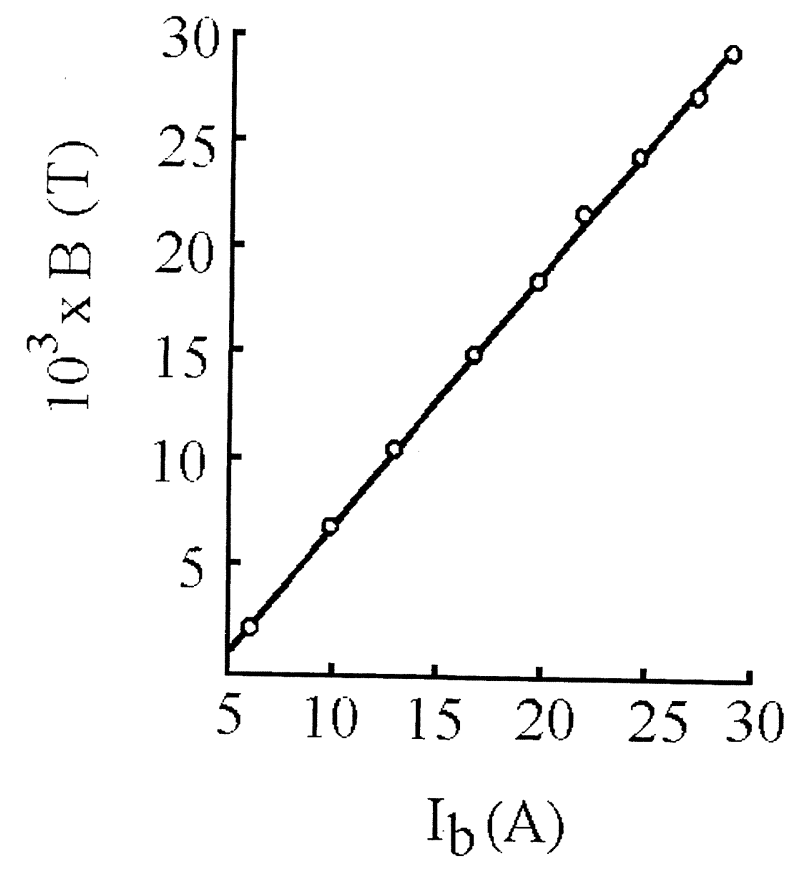

Figure 7. Dependence of the resultant magnetic field induction $B$ on the electric current intensity through the coils $l_{b}$.

Figura 7. Variación de la inducción B del campo magnético consiguiente, en función de la intensidad $\mathrm{I}_{b}$ de la corriente eléctrica en las bobinas.

Because of the cooling of the electrodes, the maximum value of the discharge electric current is $I=100 \mathrm{~A}, \mathrm{dc}$, for a voltage value on the $\operatorname{arc} U=50$ $\mathrm{V}, \mathrm{dc}$.

The mean mass temperature of the electric arc column in argon medium is estimated to be $T=$ $3,000 \mathrm{~K}^{[8]}$. Observing the trace left on the electrodes by the electric arc (Fig. 8), it is measured $r=6 \cdot 10^{-3} \mathrm{~m}, R=3.5 \cdot 10^{-2} \mathrm{~m}, d=4 \cdot 10^{-3} \mathrm{~m}$ and $\varepsilon=$ $2.5 \cdot 10^{-4} \mathrm{~m}$. For $T=3,000 \mathrm{~K}$, it can be obtained $\eta=$ $4 \cdot 10^{-4} \mathrm{~kg} \cdot \mathrm{m}^{-1} \cdot \mathrm{s}^{-1}$ and $\gamma=0.9 \mathrm{~N} \cdot \mathrm{m}^{-1}$.

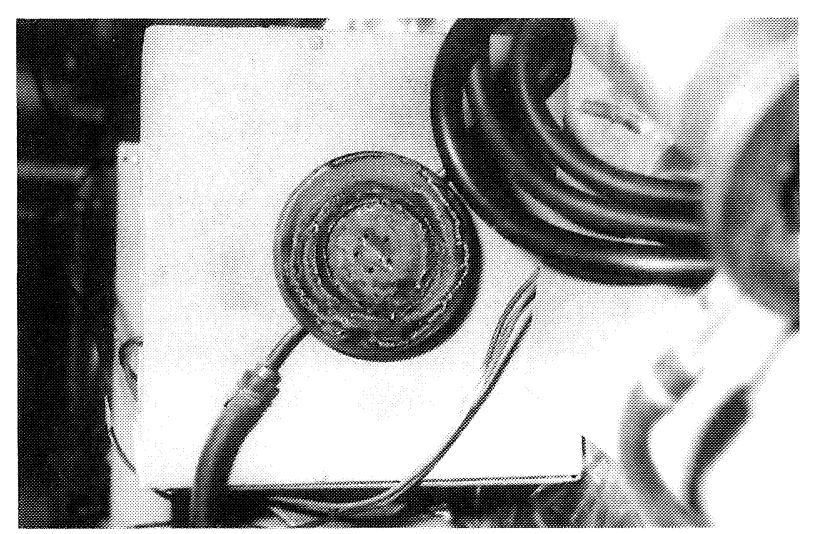

Figure 8. Traces of melt on the copper electrode surface.

Figure 8. Trazas de metal fundido sobre la superficie del electrodo de cobre.
Figure 9 displays the predicted by equation (2) and the experimental values of $v$ versus the values of the magnetic field induction $B$.

Deviations up to $\pm 20 \%$ between the measured and the theoretical values can be seen in figure 9 . These deviations occur due to the lack of precision of the rotation indicator block, and, also, due to the modification of the thermo-physical characteristics of the metal surface as a result of the heating of the electrodes.

The chamotte powder (Fig. 10), milled in a ball mill, has an equivalent maximum diameter of 30 $\mu \mathrm{m}$. The powder is introduced in the rotating electric arc at a flow rate of $3 \mathrm{~g} \cdot \mathrm{min}^{-1} \pm 10 \%$, (the argon flow rate is $5 \mathrm{Nl} \cdot \mathrm{min}^{-1}$ ). At rotation values up to $250 \mathrm{~s}^{-1}$ of the electric arc, the processing efficiency is low $(5 \pm 10 \%)$. Starting at $v=300 \mathrm{~s}^{-1}$, the powder processing efficiency increases. At $v=$ $750 \mathrm{~s}^{-1}$ the efficiency is maximum, $\phi=92 \%$. On the other hand, $v=300 \mathrm{~s}^{-1}$, the plasma of the electric arc includes the entire space between the electrodes. At $T=3,000 \mathrm{~K}$, the chamotte powder is in permanent contact with the thermal field of the plasma. Due to the surface tension in the meltargon system, spherical drops are produced and their shape is preserved as they are rapidly cooled (Fig. 11). The variation in diameters (ranging from 15 to $20 \mu \mathrm{m}$ ) is due to the dispersion of the raw material as well as to the inhomogeneous thermal field of the electric discharge. An optimal value of

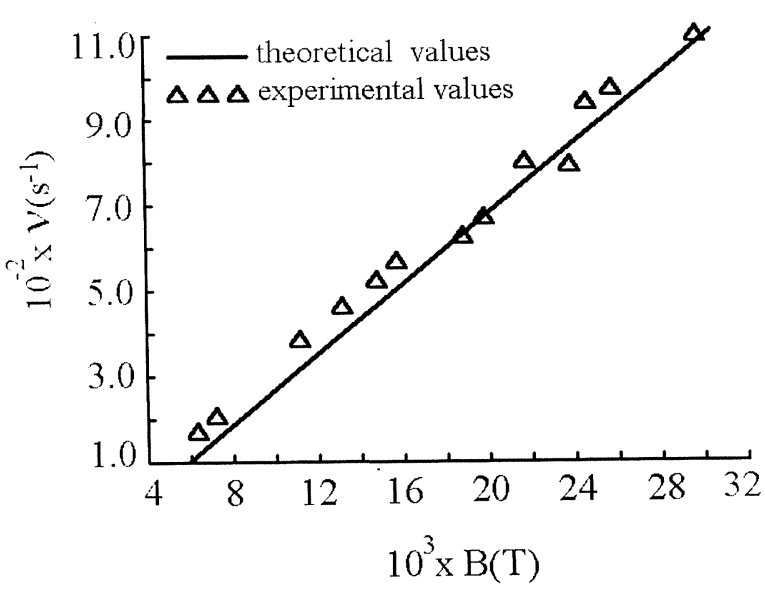

Figure 9. The magnetic field induction $B$ dependence of the electric arc rotational frequency at discharge electric current $I=100 \mathrm{~A}$, dc, plasma gas (argon) flow rate $\mathrm{D}=10 \mathrm{~N} \cdot \cdot \mathrm{min}^{-1}$.

Figura 9. Dependecia de la frecuencia y del movimiento de rotación del arco eléctrico en función del valor $B$ de la inducción del campo magnético, para una intensidad de la corriente de descarga $\mathrm{l}=100 \mathrm{~A}$; el caudal de gas (Ar): $D=$ $10 \mathrm{Nl} \cdot \mathrm{min}^{-1}$. 


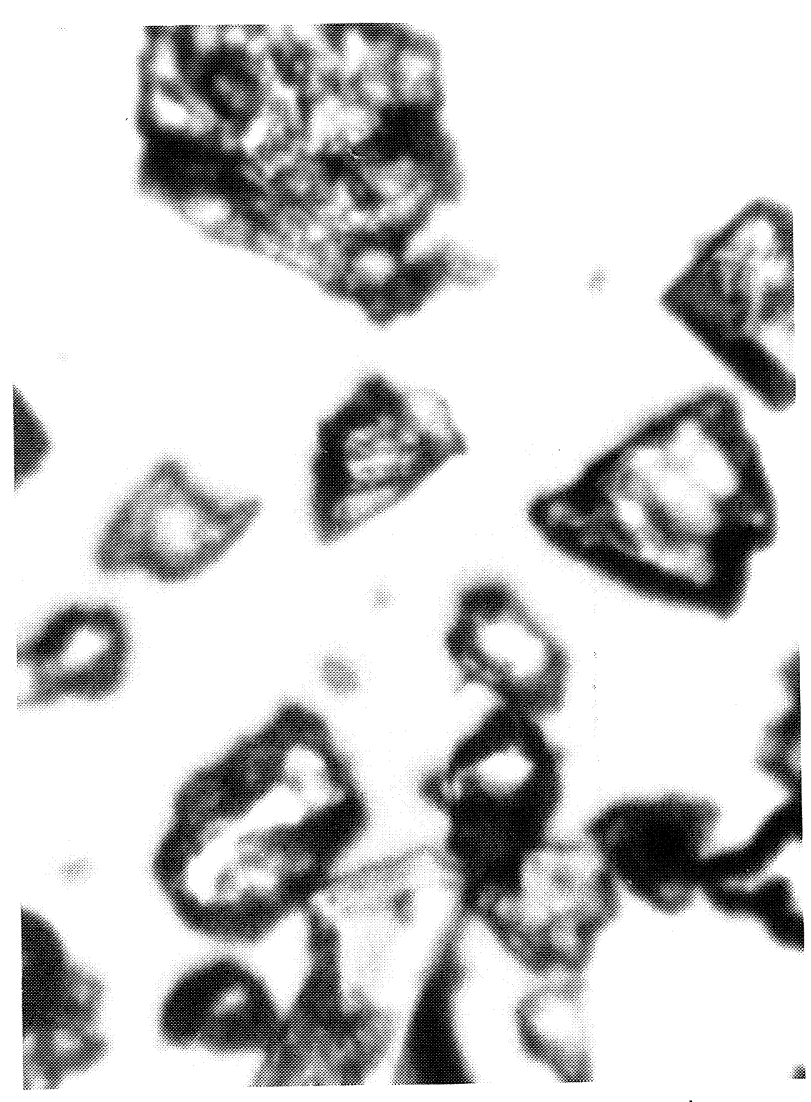

Figure 10. Mechanically processed chamotte powder .

Figura 10. Polvo de "chamota" procesada mecánicamente.

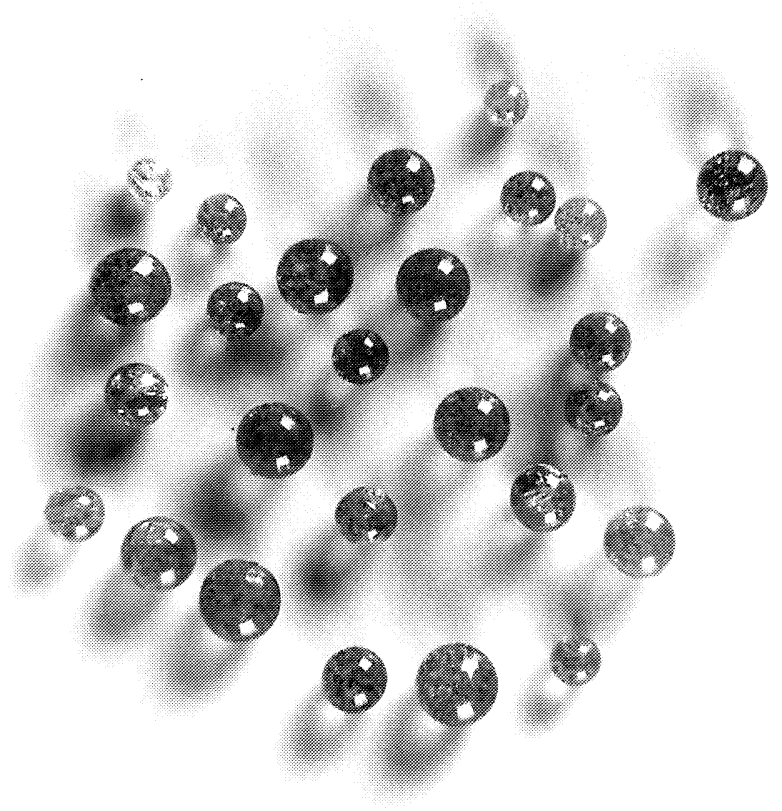

Figure 11. Particles shaped as spheres in the plasma (300x).

Figure 11. Partículas convertidas en esferas en el plasma (x300).
$3 \mathrm{~g} \cdot \mathrm{min}^{-1}$ for the mechanically milled particles is obtained. The processing efficiency suddenly decreases for flow rate values exceeding $3 \mathrm{~g} \cdot \mathrm{min}^{-1}$. A certain amount of particles stick to the electrodes leading to arc extinction.

\section{CONCLUSIONS}

- Rotating frequency of the electric arc up to $v=$ $1,000 \mathrm{~s}^{-1} \pm 5$ was obtained.

- The particles of the chamotte powder, obtained by mechanical milling, are shaped as spheres in the plasma of the rotating electric arc.

- The chamotte powder (mass flow rate $3 \mathrm{~g} \cdot \mathrm{min}^{-1}$ ) is spheroidized with an efficiency $\phi=92 \%$ in argon medium $\left(10 \mathrm{Nl} \cdot \mathrm{min}^{-1}\right)$ for an electric current intensity of $100 \mathrm{~A}$, dc, through the electric arc, and a voltage on the arc of $50 \mathrm{~V}$, dc.

- A better cooling of the electrodes and a double value of the idle voltage of the current source, should allow the spheroidization of a larger amount of particles.

\section{Acknowledgements}

The author would like to thank Nicoleta Stefu and Doru Baltateanu and Raluca Florea for the fruitful discussions for the neatly translation of this paper.

\section{REFERENCES}

[1] L. ZMIHE, Doctoral Thesis, Technische Hochschule, Aachen, 1990.

[2] P. R. DenNIS, Plasma Jet Technology NASA, 1965.

[3] C.L. Korman, H.M. LAUN and H.J. RichteR, J. Modern Phys. B10 (1996) 3167.

[4] T.H. LEEK, S. LINGARD, W.A. BULLOUGH and R.J. ATKIN, J. Modern Phys. B10 (1996) 3343.

[5] M.N. Rykaln, Pure Appl. Chem. 48 (1976) 179 and 229.

[6] I. BICA, Mesoscopic Particles (in Romanian), Mirton Press, Timisoara, Rumanía, 1997.

[7] I. BICA, Rev. Metal. Madrid 35 (1999) 126.

[8] J.F. LANCASTER, The Physics of Welding, Pergamon Press, Oxford, 1984. 